\title{
Scholarly Reprint Publishing in the United States: A New Look
}

\author{
Joseph C. Meredith
}

Results of a 1969 survey by Carol A. Nemeyer of scholarly reprint activity in the United States are reviewed in the light of subsequent trends. It is concluded that although replication of the survey is not warranted at this time, certain aspects of the genre merit continued study. The important role of academic librarians in scholarly reprint selection is stressed.

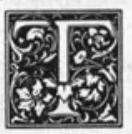

hirteen years ago Carol A. Nemeyer published Scholarly Reprint Publishing in the United States, ${ }^{1}$ which was adapted from her doctoral dissertation on the same subject. ${ }^{2}$ The work was generally hailed as timely and useful, not only as an overview of the burgeoning reprint industry but also as an aid to librarians involved in materials selection and acquisition. Since then, some of the trends noted by Nemeyer have run their course, while certain technical and financial changes have affected the policies and practices of collection building. Indeed, it has been suggested that the current situation differs sufficiently from the time of the original research (1968-70) to justify mounting an entirely new study.

Before addressing this question, it will be useful to describe the original problem and methodology employed by Nemeyer. As she indicated at the time, "Reprint publishing was found to be plagued by, and partly responsible for, serious information gaps which cloaked the industry with a veil of mystery," making it difficult to find out if a particular title had been reprinted, by whom, in what format, and at what price. $^{3}$ The sudden interest of publishers in reissuing important works long out of print was inspired not so much by production breakthroughs as by the prevailing drive of many academic libraries (some in newly founded institutions) to fill gaps and enrich their collections. This drive was fostered to some extent by interinstitutional rivalry in a climate of relative affluence. Publishers were further stimulated by the active interest in reprints shown by the American Library Association before it became apparent that such stimulus was hardly needed.

Although reprints were not a new genre, the sudden growth of the market after World War II tended to make them operate as such. This led entrepreneurs to engage in lively guessing games with no clear idea of what was needed, how to set press runs, how to price the product, and how to meet certain bibliographic obligations. Each publisher kept his own counsel, so the investigator had to extract bits of information that, taken together, could be coherently summed up. To this end Nemeyer conducted personal interviews with 37 publishers involved in the kind of scholarly programs that fell within the scope of her study, plus about 53 other persons in the book trades and the library world. She addressed a twenty-nine-item questionnaire to an additional 250 pub-

Joseph C. Meredith is a retired university professor in information science, Governors State University, University Park, Illinois 64066. 
lishers. There were 159 returns. All but 31 were within scope. As a result, she was able to compile a directory of about 300 reprint publishers, listing for each the name, address, director, date of founding, formats issued, forms issued, total number of issuances up through 1970, primary fields of interest, and (if applicable) CIP and ISBN information. The resultant "Directory of Reprint Publishers" ${ }^{\prime 4}$ filled a definite need, for in the absence of any association of reprint publishers, nothing of the sort had been compiled up to that time.

Other data derived from the interviews and questionnaire returns, and from the secondary and trade literature, were combined and interpreted to develop conclusions set forth under programs, editorial practices, production practices, marketing and distribution, and the mutual concerns of reprinters and librarians.

The scope of the survey was a troublesome issue. Although Nemeyer recognized the growing importance of foreign and international reprinting, "for practical reasons" she focused on reprint publishing in the United States. In the microform area, because of the rapid proliferation of materials, she included only nongovernmental microrepublishing specialists. She also excluded massmarket paperback titles because "the publishing concept, target audience, and distribution methods differ significantly from specialist reprint publishing. ${ }^{\prime \prime 5}$

Scholarly publishers were identified by Nemeyer as those "who specialize in the republication of books of scholarship and other OP materials intended for sale primarily, but not exclusively, to libraries and other educational institutions" and works "of interest to scholars and other serious readers." ${ }^{\prime \prime}$ All of this bothered the reviewers. Nevertheless, the general consensus on the study was as follows: "of extreme value and by far the most comprehensive on the subject ever compiled," "a valuable addition to the literature, ," "a welcome contribution on a significant development in modern publishing, ${ }^{\prime \prime}$ and an aid to "both the librarian and the reprint publisher.,"10

The book did not purport to be a librarian's guide to reprint selection. It simply presented a picture of the reprint industry and its practitioners.

During the 1960s a lively interest in reprints and reprinting was reflected in the literature. Nemeyer made good use of this interest. There has been a notable falling off of the number of journal articles on the subject since then, although the reasons are not altogether apparent, considering that reprinting has become a major component of the industry. The few articles that have appeared tend merely to restate issues already discussed by Nemeyer, such as

- the need for more disciplined choice of titles to reprint, in order to minimize duplication and to forestall unnecessary reprinting of materials readily available in the used-book trade;

- the need for more consistent pricing practices;

- the need for reproduction standards (format, size, identification); and

- the need for more comprehensive review services.

At this point one may ask what, if anything, has changed? Have any of the problems been resolved? Has the industry developed in ways that resist further study of scholarly reprint publishing? What does it all mean to librarians charged with the selection and acquisition of scholarly materials?

In her book, Nemeyer raised questions and suggested lines of inquiry for future investigation. She has kindly responded to a letter from this author asking her to comment anew on some of these points.

Regarding the scope of the original study, Nemeyer notes that a similar study should have been conducted for the international publishing scene. In any new study, she would probably eliminate microforms because the "industry has changed significantly, a reflection of technology and demand."

The 1968-70 survey was never conceived or designed as an economic survey of the industry, although its author believed "an up-to-date 'Cheney' report would be welcomed." Now she sees an increasing number of good studies on the economics of publishing and a heightened interest in the subject. This is reflected in 
the Book Industry Study Group and in the large number of publishing courses being offered.

The neglect of adequate bibliographic controls (descriptive and enumerative) by reprinters and reference book publishers alike was a serious problem at the time Scholarly Reprint Publishing in the United States was written. In discussing this, Nemeyer hoped that in coming of age the reprint industry would devote more attention to bibliographic and cataloging needs. Today her remarks are particularly germane, coming as they do from the vantage point of her current position in the $\mathrm{Li}$ brary of Congress.

Given the relative success of the cataloging in publication program and the expanded number of publishers who participate, certainly their awareness of bibliographic and cataloging needs is heightened. I also believe that indexing needs are evermore important and that the publishing industry is gaining awareness of that, pushed by the need to retrieve rather specifically from highly compacted information stored electronically, in databases, on video discs, etc. I believe that publishers will continue to need the library world's expertise in this area. $^{11}$

If a new study were to be carried out, it would be interesting to ascertain which publishers make a real effort not only to participate in bibliographic systems but also to ensure that their product is consistent with some kind of standard criteria such as those proposed by the Rare Books Libraries Conference on Facsimiles in 1972. ${ }^{12}$ One cannot be sure, but there seems some likelihood that reprinters who have become divisions of the large conglomerates would make a good showing.

To revert to the main question: What is the shape of the reprint industry today? Is it still distinct enough to be studied as a separate entity? Probably not, although to confirm this would entail another survey. Many houses that are generally known for new works and new editions of older works have ventured into the reprint field, either directly or through subsidiaries, while typical reprint publishers can and often do publish new works of promise. In other words, the reprint industry as such seems to have become too amorphous to permit a disciplined approach. One effect of this is that there no longer seems to be a need for a separate organization of reprinters. ${ }^{13}$

This does not mean, however, that reprints themselves cannot be studied as a genre.

Definition of the word reprint remains a problem, as manifested by the assorted versions quoted in appendix A of Nemeyer's study ${ }^{14}$ and to the more recent offerings of Yanchisen ${ }^{15}$ and Wiseman. ${ }^{16}$ For practical purposes, however, we could say that in order to be considered a reprint, an issuance must faithfully reproduce in some printed form the text of a single printed original. Any work reproduced from other than a single printed original would count as an edition rather than a reprint, regardless of the presence or absence of new editorial matter. On the other hand, we would not exclude works enriched by new prefatory materials, such as indexes, as long as the material did not intrude on the pages of reprinted text. Freedman would exclude works issued by the original publisher, but this distinction is not very compelling and runs counter to most trade parlance. Nor is there any point in excluding piracies, which after all were among the forebears of reprinting as we know it and are still with us in some corners of the world. ${ }^{17}$

In defining the word scholarly, we should adhere to its Latin roots-the idea of the school and of acquiring knowledge. A book whose subject matter fits this purpose, as opposed to one designed to entertain or to play on the emotions, is clearly one of scholarship. Publishers themselves seem to have little difficulty distinguishing between the two. One need not be confused by scholarly interest in trash, for example Vina Delmar's Bad Girl (New York: Grosset \& Dunlap, 1928), because in such a case it is the work representing itself that is the object of study; it doesn't stand alone as a scholarly production. In borderline cases, subjective judgment will govern, but the criterion seems valid and will serve for practical purposes.

In a study concentrating on scholarly reprints as a genre, rather than as a some- 
what casual product of a particular segment of the publishing industry, a shift in emphasis will be inevitable. It will be toward the market, toward the customers, chiefly academic libraries and librarians, whose needs and choices determine what can be successfully reprinted and sold. These same customers have heretofore been accorded a rather passive role in the scholarly reprint system. The shift would help deal with the questions posed in 1973 by one writer: Does the demand create the supply; does the supply create the demand; or are both elements at work? ${ }^{18}$ Put another way-What is the nature and extent of the demand in relation to reprint publishing?

In her 1969 questionnaire, Nemeyer asked reprint publishers to indicate the primary basis on which they selected titles for publication: (a) personal knowledge of subject fields, $(b)$ awareness of unmet demands for copies on the used book market, (c) appearance of titles on recommended book lists, $(d)$ advice from paid consultants, $(e)$ advice from faculty, librarians, scholars, and $(f)$ other. ${ }^{19}$ The results were inconclusive, as many firms checked more than one category. Many respondents claimed to use more subjective criteria, such as intuition or feel for the market. Some indicated book-list recommendations as a criterion, but none admitted to using them exclusively. ${ }^{20}$ However, book lists were probably used more heavily than indicated, especially in view of the way in which the output of reprint publishers had matched many books listed in Books for College Libraries (BCL). ${ }^{21}$

The significance of $B C L$ as an influence on book selection can be traced back to Charles Shaw's original List of Books for College Libraries (1932) ${ }^{22}$ and its supplement (1940). ${ }^{23}$ The 1932 list was basically prescriptive, as a determinant in connection with grants in aid to college libraries by the Carnegie Corporation of New York. It was also expected to serve as a selection guide; ${ }^{24}$ the method of compilation, however, left something to be desired. Carnovsky warned, "It would be extremely dangerous for any librarian to follow the list blindly in his purchases, as though it were the final authority instead of a first aid." 25

The introduction to Shaw's Supplement covering the years 1931-38, again published by the American Library Association, was silent as to purpose, but the addition of review citations to most of the entries seemed to endorse its use as a selection tool. The Depression of the 1930s and the exclusion of out-of-print items from the list precluded the kind of response generated by $B C L$ later on, when new library collections were being created, old ones enlarged, and reprint publishing became big business.

Similarly, the $B C L$ list originated in a special requirement: to identify about fifty thousand titles for three identical, basic, self-contained libraries for three new campuses of the University of CaliforniaIrvine, Santa Cruz, and San Diego. Again the American Library Association was the publisher, albeit with a note of caution:

This list does not claim to be a list of the best books or basic list for any college library, for selection of books for a college library must be made in terms of the needs of that particular institution. ${ }^{26}$

However, the list immediately became regarded as the authoritative selection tool and created an enormous demand for the out-of-print titles that made up 40 percent of all those listed. ${ }^{27}$ As asserted in CHOICE, this gladdened "the hearts of reprinters who immediately set about scouring the entries for possible publications, while trade houses made plans to reissue various OP titles in their back lists. Voigt and Treyz have influenced needed publishing, and libraries will prosper that much more. ${ }^{\prime 28}$ CHOICE even provided a long list of reissued titles in English and American literature to illustrate the importance of $B C L$ in the reprint field.

All this may have been to the good, because of the high quality of the titles selected and because the list went through a final revision before publication to make it generally more useful to libraries other than the three for which it was designed. Yet one is tempted to believe that its very excellence may have diminished respect 
for the art and practice of retrospective book selection performed by librarians.

The second edition of $B C L$ appeared in 1975 , midpoint in a decade of increasing financial stringency. It would be interesting to learn what effect the second edition had on retrospective buying and on the programs of reprint publishers. Nemeyer favors such a study. ${ }^{29}$ Actually, we need to know much more about how these lists have been used and how they are affected by the march of attrition and decay, as discussed by Gosnell in his review of the Shaw Supplement. ${ }^{30}$

Any new study should include an actual sampling of scholarly reprints analyzed according to quantity, quality, price, and such things as

- whether or not they have been provided with new introductory material, notes, or indexes;

- how they happened to be chosen for reprinting;

- status of the original publication;

- subject orientation; and

- intended audience.

One might even conduct a study similar to the one of Leonard Jolley at the University of Western Australia, who randomly chose twelve current reprints, analyzed each in terms of scholarly needs, demand, and alternate availability, and came up with the following tally for the books: ${ }^{31}$

- highly specialized and not superseded (1)

- already available (2)

- of no value (3)

- once of unquestioned value but current importance is questionable (3)

- value questionable (3)

The bibliographical control of reprints is improving, thanks to Guide to Reprints ${ }^{32}$ and International Bibliography of Reprints. ${ }^{33}$ The former includes titles of books and journals submitted by about four hundred republishing firms throughout the world. In order to qualify, the works must be reproduced by photolithography, with no composition involved except for such things as additions to the title page; must not measure less than 75 percent of the size of the original; must be reproduced in an edition of at least two hundred copies; must be listed in a catalog or leaflet distributed to the general public; and must actually have been reprinted and be available for delivery. For some reason, an earlier requirement that a reprint be bound has been removed.

Most entries in the Guide consist only of author, title, date of original publication, name of reprint publisher, price, and ISBN. The International Bibliography of Reprints has more substantial entries: author, title, complete original imprint, complete reprint imprint, pagination, applicable series information, and price. Criteria for inclusion are similar, except that reprints issued by the original publisher are excluded from the International Bibliography.

The Guide is revised and reissued annually, while the International Bibliography is updated by the quarterly Bulletin of Reprints. By the nature of such things, however, the Guide should be more consistently current, since 80 percent of the entries in the International Bibliography require some research in addition to reprinter-furnished information.

Most librarians with book-selection and collection-building responsibilities have opinions about the flood of reprinters' brochures and catalogs, typically subjectoriented packages that certain publishers seem to think are irresistible. Certainly such a package may simplify crash buying for a new academic program, but this kind of need rarely occurs. Usually close collaboration between librarian and faculty about appropriate titles is sufficient for determining most needs.

Without examining individual titles, one cannot ascertain the number of books on the list that have little scholarly merit. Besides, if the subject is of great current interest, many of the old standbys are apt to be superseded soon or at least brought up to date in new editions. Also some subjects for which demand has increased sharply may just as quickly exhibit a sharp decrease in demand. This happened in the field of Africana:

Many publishers rushed headlong into the field with their vision encompassing little more than 
dollar signs. Indicative of this is the widespread misreading of the needs and potential of the market in such reprints. Accordingly, a bubble which rapidly overinflated may now be said to have burst. ${ }^{34}$

\section{CONCLUSION}

A comprehensive survey of scholarly reprinting in the United States similar to that conducted by Carol Nemeyer is not needed and would not be particularly suited to the changes that have taken place over the past fourteen years, such as the gradual emergence of reprinting into the mainstream of publishing, the stabilization of production standards and costs, and improved bibliographical coverage. Production and marketing have become so international in scope that any study limited to domestic practice would lose meaning.

As has been pointed out, certain areas merit continued study, with perhaps a shift in emphasis away from the industry and toward a better understanding of the reprint genre as an entity and of the ways in which the link between users and producers can be strengthened.

The responsibility of library professionals as users and gatekeepers should be stressed. Indeed, the importance of this role should be emphasized because among the dwindling number of functions that automation cannot take over is the "art and practice" of book selection.

The spate of reprints in the 1960 s led Nemeyer to ask publishers to react to the statement, "The well is running dry." Answers varied from "yes" to "hell, no." One respondent even lamented: "After the Voigt-Treyz book, there is nothing left to do." But several publishers felt certain they could continue to find a market for an old title intelligently chosen. ${ }^{35}$ There can be no better way of concluding this article than by quoting Nemeyer's opinion today:

I believe the well never runs dry when it comes to scholarly materials. What is current today becomes immediately retrospective. Disciplines change but scholars' needs remain various and intriguing. ${ }^{36}$

\section{REFERENCES}

1. Carol A. Nemeyer, Scholarly Reprint Publishing in the United States (New York: Bowker, 1972).

2. "Scholarly Reprint Publishing in the United States" (Ph.D. diss., Columbia Univ., 1971).

3. Nemeyer, Scholarly Reprint Publishing, p.1.

4. Ibid., appendix E, p.174-213.

5. Ibid., p.17.

6. Ibid., p.14-15.

7. CHOICE, review, 10:72 (Mar. 1973).

8. Gunther J. Herman, review, Library Quarterly 43:179 (Apr. 1973).

9. Robert E. Cazden, review, Library Resources \& Technical Services 18:301-2 (Summer 1974).

10. Charles Aston, Jr., review, Library Journal 98:141 (Jan. 15, 1973).

11. Carol A. Nemeyer, letter to the author, March 3, 1983.

12. "Rare Book Reprint Standards Are Made Available," Library Journal 97:2682 (Sept. 1, 1972).

13. Nemeyer now concurs in this; see reference 11.

14. Nemeyer, Scholarly Reprint Publishing, p.159-61.

15. Daniel A. Yanchisen, "Old Books, New Faces," North Carolina Libraries 34:11-13 (Spring 1976).

16. J. A. Wiseman, "The Reprint Bulletin-Book Reviews: Another Librarian's View," Reprint BulletinBook Reviews 18:2-3 (Fall 1973).

17. Joseph J. Nerbonne, "Book Pirating Is Lively on Formosa but Authorized Reprints Are Making Gains," Publishers Weekly 214:28-30 (Aug. 7, 1978).

18. Hendrik Edelman, review, College \& Research Libraries 34:163 (Mar. 1973).

19. Nemeyer, Scholarly Reprint Publishing, p.172.

20. Ibid., p.73-75.

21. Melvin Voigt and Joseph H. Treyz, eds., Books for College Libraries, a Selected List of Approximately 53,400 Titles Based on the Original Selection Made for the University of California's New Campus Program 
and Selected with the Assistance of College Teachers, Librarians, and Other Advisers (Chicago: American Library Assn., 1967).

22. Charles B. Shaw, A List of Books for College Libraries: Approximately 14,000 Titles Selected on the Recommendation of 200 College Teachers, Librarians, and Other Advisors, Prepared by Charles B. Shaw for the Carnegie Corporation of New York Advisory Group on College Libraries, William Warner Bishop, Chairman, 2d preliminary ed, (Chicago: American Library Assn., 1931).

23. Charles B. Shaw, A List of Books for College Libraries, 1931-38 (Chicago: American Library Assn., 1940).

24. William Warner Bishop, preface, in A List of Books for College Libraries, by Charles B. Shaw (Chicago: American Library Assn., 1931), p.v.

25. Leon Carnovsky, review, Library Quarterly 2:161 (Apr. 1932).

26. Voigt and Treyz, Books for College Libraries, p.v.

27. Lee Ash, review, Library Journal, 92:3390,3392 (Oct. 1967).

28. "Seminal Start," CHOICE 4:797-98 (Oct. 1967).

29. Nemeyer, letter to the author.

30. Charles F. Gosnell, review, Library Journal 65:531-32 (June 15, 1940).

31. Leonard Jolley, "Some Reflections on Reprints," Australian Academic and Research Libraries 4:80-84 (June 1973).

32. Ann S. Davis, ed., Guide to Reprints, (Kent, Conn.: Guide to Reprints, Inc., 1967- ). Originally edited by A. J. Diaz and published by Microcard Editions.

33. Christa Gnirss, ed., International Bibliography of Reprints (Munich: Verlag Dokumentation, 1976- y.

34. J. A. Casada, "Reflections in a Burst Bubble: Africana Reprints," Reprint Bulletin-Book Reviews 21:1-3 (Spring 1976).

35. Nemeyer, Scholarly Reprint Publishing, p.79-81.

36. Nemeyer, letter to the author. 